\title{
Volatility Jumps: The Role of Geopolitical Risks ${ }^{\#}$
}

\author{
Konstantinos Gkillas ${ }^{*}$, Rangan Gupta ${ }^{* *}$ and Mark E. Wohar ${ }^{* * *}$
}

\section{Highlights}

- We analyse the role of geopolitical risks (GPR) in predicting volatility jumps in the DJIA.

- We examine the period 1899:01 to 2017:12, with the jumps having been computed based on daily data over the same period.

- Standard linear Granger causality test failed to detect any evidence of GPRs causing volatility jumps

- Using a nonparametric causality-in-quantiles test detect overwhelming evidence of GPRs predicting volatility jumps of the DJIA over its entire conditional distribution.

\begin{abstract}
In this paper we analyse the role of a news-based index of geopolitical risks (GPRs), in predicting volatility jumps in the Dow Jones Industrial Average (DJIA) over the monthly period of 1899:01 to 2017:12, with the jumps having been computed based on daily data over the same period. Standard linear Granger causality test failed to detect any evidence of GPRs causing volatility jumps. But given strong evidence of nonlinearity and structural breaks between jumps and GPRs, we next used a nonparametric causality-in-quantiles test, since the linear model is misspecified. Using this data-driven robust approach we were able to detect overwhelming evidence of GPRs predicting volatility jumps of the DJIA over its entire conditional distribution. In addition, a cross-quantilogram analysis shows that what matters most for increases in volatility jumps are relatively higher GPRs than lower values of the same.
\end{abstract}

Keywords: Stock Market Volatility Jumps, Geopolitical Risks.

JEL Codes: C22, G10.

\section{Introduction}

Financial market volatility is an important input in investment decisions, option pricing and financial market regulation (Poon and Granger, 2003). Given this, market participants care not only about the nature of volatility, but also of its level, with all traders making the distinction between good and bad volatilities (Giot et al., 2010). Good volatility is directional, persistent and relatively easy to anticipate. Bad volatility however, is jumpy and relatively difficult to foresee. Hence, good volatility can be associated with the continuous and persistent part, while bad volatility captures the discontinuous and jump component. In this regard, it has been stressed

\footnotetext{
\# We would like to thank an anonymous referee for many helpful comments. However, any remaining errors are solely ours.

* Department of Business Administration, University of Patras, University Campus, Rio, P.O. Box 1391, 26500

Patras, Greece. Email: Email: gillask@upatras.gr or gillask@gmail.com.

** Department of Economics, University of Pretoria, Pretoria, 0002, South Africa. Email: rangan.gupta@up.ac.za.

*** Corresponding author. College of Business Administration, University of Nebraska at Omaha, 6708 Pine Street, Omaha, NE 68182, USA; School of Business and Economics, Loughborough University, Leicestershire, LE11 3TU, UK. Email: mwohar@unomaha.edu.
} 
that jumps in volatility can improve the overall fit of volatility models (Duffie et al., 2000; Eraker et al., 2003; Broadie et al., 2007; Todorov and Tauchen, 2011). Understandably, a large literature has developed trying to not only model volatility jumps, but also attempting to explain the causes behind such jumps based on financial variables (Caporin et al., 2016). Related to this line of research, Boudoukh et al., (2015) and Baker et al., (2018), motivated by the early work of Cutler et al., (1989), have been using text search to connect stock jumps to news.

Against this backdrop, the objective of this paper is to use a news-based index of geopolitical risks (GPRs), as developed by Caladara and Iacoviello (2017), to predict volatility jumps in the Dow Jones Industrial Average (DJIA) over the monthly period of 1899:01 to 2017:12, with the jumps having been computed based on daily data over the same period. Given that asset prices are functions of the state of the economy, which in turn is affected by GPRs (Caldara and Iacoviello, 2017), recently, studies like Apergis et al., (2017), Caladara and Iacoviello (2017), Balcilar et al., (forthcoming), Bouras et al., (forthcoming), and Bouri et al., (forthcoming) have related GPRs with stock and bond market returns and volatility, with them indicating that GPRs tend to have a more pronounced impact on volatility than returns. As indicated above, given the importance of jumps in volatility modelling, especially bad volatility, we, to the best of our knowledge, make the first attempt in this paper to predict volatility jumps using information on GPRs. If GPRs do predict jumps, then we can say that GPRs tend to affect bad volatility, and hence, we would be able to provide an explanation as to why GPRs tend to affect volatility more than returns.

For our predictability analysis, we rely on the nonparametric causality-in-quantiles test of Jeong $e t$ al., (2012), and hence, in the process capturing various phases (sizes) of volatility jumps. Understandably, this causality-in-quantiles approach is inherently a time-varying approach as various parts of the conditional distribution of volatility jumps would relate to various points in time associated with the evolution of jumps. The causality-in-quantile approach has the following two novelties: Firstly, it is robust to misspecification errors as it detects the underlying dependence structure between the examined time series, which could prove to be particularly important as we show that volatility jumps is nonlinearly associated with GPRs, which is not surprising given ample evidence of financial market variables being nonlinearly related with its predictors (Balcilar et al., 2017). Secondly, via this methodology, we are able to test not only for causality-in-mean (1st moment) as in popular nonlinear causality tests of Heimstra and Jones (1994), and Diks and Panchenko (2005, 2006), but also for causality that may exist in the tails of 
the joint distribution of the variables. This is again of paramount importance since our dependent variable, i.e., volatility jumps is shown to have fat-tails, as outlined also in Bollerslev et al., (2013). In addition, we also use a cross-quantilogram analysis as proposed by Han et al., (2016), which in turn allows us to qualify our results from the causality-in-quantiles test further, by providing us information of the importance of the size of GPRs, and directional predictability.

The remainder of the paper is organized as follows: Section 2 lays out the basics of the econometric methodologies involving volatility jumps and the causality-in-quantiles approach; Section 3 presents the data and results, with Section 4 concluding the paper.

\section{Econometric Methodologies}

\subsection{Volatility Jumps}

We employ daily log returns $R_{t, i}$ of the DJIA to estimate the monthly median realized variance $\left(M R V_{t}\right)$. In each month $t$, we retrieve a monthly point estimate of the $M R V_{t}$ by employing all daily returns. We calculate monthly volatility by the median realized variance, $M R V_{t}$, which is the best alternative jump-robust estimator of realized variance, as introduced by Andersen et al. (2012), as follows:

$M R V_{t}=\gamma\left(\frac{N}{N-2}\right) \sum_{i=1}^{N-1} \operatorname{med}\left(\left|R_{t, i-1}\right|,\left|R_{t, i}\right|,\left|R_{t, i+1}\right|\right)^{2}$

where, $\gamma=\left(\frac{\pi}{6-4 \sqrt{3}+\pi}\right), R_{t, i}$ is the daily return for day $i$ within month $t$ and $i=1, \ldots N$, where $N$ is the total number of daily observations within a month.

We also examine the determinants of monthly jumps series. Following, Bekaert and Hoerova (2014) we employ the threshold bipower variation $\left(T B P V_{t}\right)$ as a jump-free volatility estimator as defined in Corsi et al. (2010), as follows:

$T B P V_{t}=\sum_{i=2}^{N}\left|R_{t, i-1}\right|,\left|R_{t, i}\right| I_{\left\{\left|R_{t, i-1}\right|^{2} \leq \theta_{i-1}\right\}} I_{\left\{\left|R_{t, i}\right|^{2} \leq \theta_{i}\right\}}$

where $I_{\{\cdot\}}$ is the indicator function and the threshold function, $R_{t, i}$ is the daily return series and $t$ represents the time in months. 
We calculate the jump statistic $\left(Z J_{t}^{(T B P V)}\right)$ following Duong and Swanson (2015), as follows:

$Z J_{t}^{(T B P V)}=\sqrt{N} \frac{\left(M R V_{t}-T B P V_{t}\right) M R V_{t}^{-1}}{\left[\left(\xi_{1}^{-4}+2 \xi_{1}^{-2}-5\right) \max \left\{1, T Q_{t} T B P V_{t}^{-2}\right\}\right]^{1 / 2}}$

where $T Q_{t}$ is the realized tripower quarticity which is $T Q_{t}=N \xi_{4 / 3}^{-3} \sum_{i=1}^{N}\left|R_{t, i}\right|^{4 / 3}\left|R_{t, i+1}\right|^{4 / 3}\left|R_{t, i+2}\right|^{4 / 3}$ and converges in probability to integrated quarticity. The $Z J_{t}^{(T B P V)}$ statistic follow a normal gaussian distribution.

A jump is considered to be significant if the $Z J_{t}^{(T B P V)}$ exceeds the appropriate critical value of the standard gaussian distribution, denoted by $\Phi_{a}$, at a $a$ significant level. The jump component of volatility in monthly frequency is:

$J U M P_{t}^{(T B P V)}=\left|M R V_{t}-T B P V_{t}\right| I_{\left\{z J_{t}^{(T B P V)}>\Phi_{a}\right\}}$

where $I_{\{\cdot\}}$ represents an indicator function of the $Z J_{t}^{(T B P V)}$ exceeds of a given critical value of a Gaussian distribution.

\subsection{Causality-in-Quantiles}

This sub-section provides a brief description of the quantile based methodology based on the framework of Jeong et al. (2012). As mentioned earlier, this approach is robust to extreme values in the data and captures general nonlinear dynamic dependencies. Let $y_{t}$ denote volatility jumps and $x_{t}$ denote the predictor variable, in our case the index capturing GPRs (as described in detail in the Data segment of the paper).

Formally, let $Y_{t-1} \equiv\left(y_{t-1}, \ldots, y_{t-p}\right), X_{t-1} \equiv\left(x_{t-1}, \ldots, x_{t-p}\right), Z_{t}=\left(X_{t}, Y_{t}\right)$ and $F_{y_{t} \mid Z_{t-1}}\left(y_{t}, Z_{t-1}\right)$ and $F_{y_{t} \mid Y_{t-1}}\left(y_{t}, Y_{t-1}\right)$ denote the conditional distribution functions of $y_{t}$ given $Z_{t-1}$ and $Y_{t-1}$, respectively. If we denote $Q_{\theta}\left(Z_{t-1}\right) \equiv Q_{\theta}\left(y_{t} \mid Z_{t-1}\right)$ and $Q_{\theta}\left(Y_{t-1}\right) \equiv Q_{\theta}\left(y_{t} \mid Y_{t-1}\right)$, we have $F_{y_{t} \mid Z_{t-1}}\left\{Q_{\theta}\left(Z_{t-1}\right) \mid Z_{t-1}\right\}=\theta$ with probability one. Consequently, the (non)causality in the -th quantile hypotheses to be tested can be specified as:

$$
\begin{aligned}
& H_{0}: P\left\{F_{y_{t} \mid Z_{t 1}}\left\{Q\left(Y_{t 1}\right) \mid Z_{t 1}\right\}=\right\}=1, \\
& H_{1}: \quad P\left\{F_{y_{t} \mid Z_{t 1}}\left\{Q\left(Y_{t 1}\right) \mid Z_{t 1}\right\}=\right\}<1 .
\end{aligned}
$$


Jeong et al. (2012) employ the distance measure $J=\left\{\varepsilon_{t} E\left(\varepsilon_{t} \mid Z_{t-1}\right) f_{z}\left(Z_{t-1}\right)\right\}$, where $\varepsilon_{t}$ is the regression error term and $f_{z}\left(Z_{t-1}\right)$ is the marginal density function of $Z_{t-1}$. The regression error $\varepsilon_{t}$ emerges based on the null hypothesis in (1), which can only be true if and only if $E\left[1\left\{y_{t} \leq Q_{\theta}\left(Y_{t-1}\right) \mid Z_{t-1}\right\}\right]=\theta$ or, equivalently, $1\left\{y_{t} \leq Q_{\theta}\left(Y_{t-1}\right)\right\}=\theta+\varepsilon_{t}$, where $\mathbf{1}\{\rtimes$ is an indicator function. Jeong et al. (2012) show that the feasible kernel-based sample analogue of $\boldsymbol{J}$ has the following form:

$$
\hat{J}_{T}=\frac{1}{T(T 1) h^{2 p}} \sum_{t=p+1}^{T} \sum_{s=p+1, s \neq t}^{T} K\left(\frac{Z_{t 1} Z_{s 1}}{h}\right) \hat{t} \hat{s} .
$$

where $K(\cdot)$ is the kernel function with bandwidth $h, T$ is the sample size, $p$ is the lag order, and ${ }_{t}$ is the estimate of the unknown regression error, which is estimated as follows:

$$
\hat{t_{t}}=1\left\{y_{t} \quad Q\left(Y_{t 1}\right)\right\} .
$$

$\hat{Q}_{\theta}\left(Y_{t-1}\right)$ is an estimate of the $\theta^{t h}$ conditional quantile of $y_{t}$ given $Y_{t-1}$, and we estimate $\hat{Q}_{\theta}\left(Y_{t-1}\right)$ using the nonparametric kernel method as

$$
\hat{Q}_{\theta}\left(Y_{t-1}\right)=\hat{F}_{y_{t} \mid Y_{t-1}}^{-1}\left(\theta \mid Y_{t-1}\right)
$$

where $\hat{F}_{y_{t} \mid Y_{t-1}}\left(y_{t} \mid Y_{t-1}\right)$ is the Nadarya-Watson kernel estimator given by

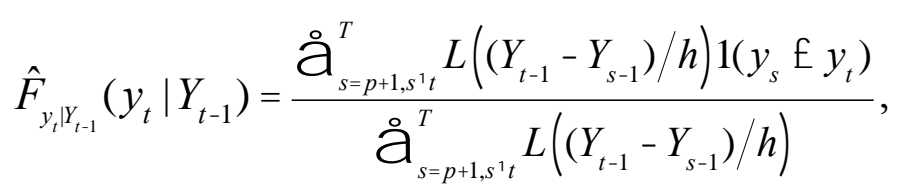

with $L(\cdot)$ denoting the kernel function and $h$ the bandwidth.

The empirical implementation of causality testing via quantiles entails specifying three important choices: the bandwidth $h$, the lag order $p=4$, and the kernel type for $K(\cdot)$ and $L(\cdot)$ respectively. In this study, we make use of lag order of one based on the Schwarz Information Criterion (SIC). Note that, when it comes to choosing lags, the SIC is considered to be parsimonious compared to other lag-length selection criteria. The SIC helps overcome the issue of over-parameterization usually arising with nonparametric frameworks. The bandwidth value is chosen by employing the least squares cross-validation techniques. ${ }^{1}$ Finally, for $K(\cdot)$ and $L(\cdot)$ Gaussian-type kernels was employed.

\footnotetext{
${ }^{1}$ For each quantile, we determine the bandwidth $h$ using the leave-one-out least-squares cross validation method of Racine and Li (2004) and Li and Racine (2004).
} 


\section{Data and Results}

Monthly data on geopolitical risk (GPR) is based on the work of Caldara and Iacoviello (2017). ${ }^{2}$ The GPR index reflects automated text-search results of the electronic archives of 3 national newspapers: The Chicago Tribune, The New York Times, and The Washington Post. Caldara and Iacoviello (2017) then calculate the index by counting the number of articles related to geopolitical risk in each newspaper for each month (as a share of the total number of news articles). The index is then normalized to average a value of 100 in the 2000-2009 decade.

The search identifies articles containing references to six groups of words: Group 1 includes words associated with explicit mentions of geopolitical risk, as well as mentions of militaryrelated tensions involving large regions of the world and a U.S. involvement. Group 2 includes words directly related to nuclear tensions. Groups 3 and 4 include mentions related to war threats and terrorist threats, respectively. Finally, Groups 5 and 6 aim at capturing press coverage of actual adverse geopolitical events (as opposed to just risks) which can be reasonably expected to lead to increases in geopolitical uncertainty, such as terrorist acts or the beginning of a war.

As indicated above in Sub-section 2.1, we use daily returns of the DJIA to arrive at the monthly volatility jump values. Stock returns are computed as the logarithmic first difference of the daily DJIA stock price index, with data on the DJIA stock index obtained from the Global Financial Database. The choice of the DJIA was natural, given the availability of historical daily data stretching as far back as $2^{\text {nd }}$ of May, 1885. Note that our analysis covers the monthly period of 1899:01 to 2017:12 (i.e., 1428 observations), with the start and end date being purely driven by the availability of data on the GPRs index. Figures A1(a) and A1(b) in the Appendix plots the volatility jump variable and the GPR index respectively, while Table A1 reports the summary statistics of the two variables under consideration. As can be seen from this table, both jump (JUMP) and GPR are positively skewed and have excess returns, resulting in non-normal distributions, as indicated by the overwhelming rejection (at 1 percent level of significance) of the null of normality under the Jarque-Bera test. The heavy-tail of the unconditional distribution of volatility jumps provide a preliminary justification for the causality-in-quantiles test used in the empirical analysis.

Before we discuss the findings from the causality-in-quantiles tests, for the sake of completeness and comparability, we first conducted the standard linear Granger causality test, with a lag-length

\footnotetext{
${ }^{2}$ The data is available for download from: https://www2.bc.edu/matteo-iacoviello/gpr.htm.
} 
of four, as determined by the SIC. The resulting $\chi^{2}(4)$ statistic yielded a value of 2.4839 , with a $p$ value of 0.6475 , suggesting that the null that GPR does not Granger causes volatility jumps cannot be rejected. Therefore, based on the standard linear test, one would conclude of no significant GPRs related effects on DJIA volatility jumps.

Given the insignificant results obtained from linear causality tests, we next statistically examine the presence of nonlinearity and structural breaks in the relationship JUMP and GPR. Nonlinearity and regime changes, if present, would further motivate the use of the nonparametric quantiles-in-causality approach, as the quantiles-based test would formally address nonlinearity and structural breaks in the relationship between the two variables under investigation. For this purpose, we apply the Brock et al., (1996, BDS) test on the residuals from the jump equation involving four lags of JUMP and GPR. Table A2 in the Appendix presents the results of the BDS test of nonlinearity. As shown in this table, we find strong evidence, at highest level of significance, for the rejection of the null of i.i.d. residuals at various embedded dimensions $(m)$, which in turn, is indicative of nonlinearity in the relationship JUMP and GPR. To further motivate the causality-in-quantiles approach, we next used the powerful UDmax and WDmax tests of Bai and Perron (2003), to detect 1 to $M$ structural breaks in the relationship between $J$ and GPRs, allowing for heterogenous error distributions across the breaks. When we applied these tests again to the jump equation involving four lags of JUMP and GPR, we detected five breaks: 1930:10, 1970:11, 1976:12, 1997:02, and 2003:07. These finding indicate that, the results based on the linear Granger causality test, cannot be deemed robust and reliable.

Given the strong evidence of nonlinearity and structural breaks in the relationship between volatility jumps and GPRs, we now turn our attention to the causality-in-quantiles test, which is robust to linear misspecification due to its nonparametric (i.e., data-driven) approach. As can be seen from Figure 1, which reports this test for the quantile range of 0.05 to 0.95 , the null that GPR does not Granger causes JUMP is overwhelmingly rejected at the 5 percent level of significance (given the critical value of 1.96), except at the lowest quantile, where the rejection of the null holds at the 10 percent level of significance (given the critical value of 1.645). In fact the null is rejected at the 1 percent level of significance (given the critical value of 2.575) over the quantile range of 0.20 to 0.90 . In other words, when we account for nonlinearity and structural breaks using a nonparametric approach, we are able to find strong evidence of predictability emanating from GPRs onto volatility jumps of the DJIA, with the highest impact at the quantile of 0.30 , unlike what was observed under the linear framework. To put it alternatively, we observe 
that GPRs can predict volatility jumps of the DJIA, irrespective of the magnitude of the jumps as captured by the various quantiles of the conditional distribution of JUMP., Recalling that the literature tends to suggest that GPRs mainly drive volatility, based on our results we can now say that the channel through which this happens is that GPRs affect jumps, and hence, bad volatilities.

Figure 1. Causality-in-Quantiles Test Results for DJIA Volatility Jumps due to GPRs

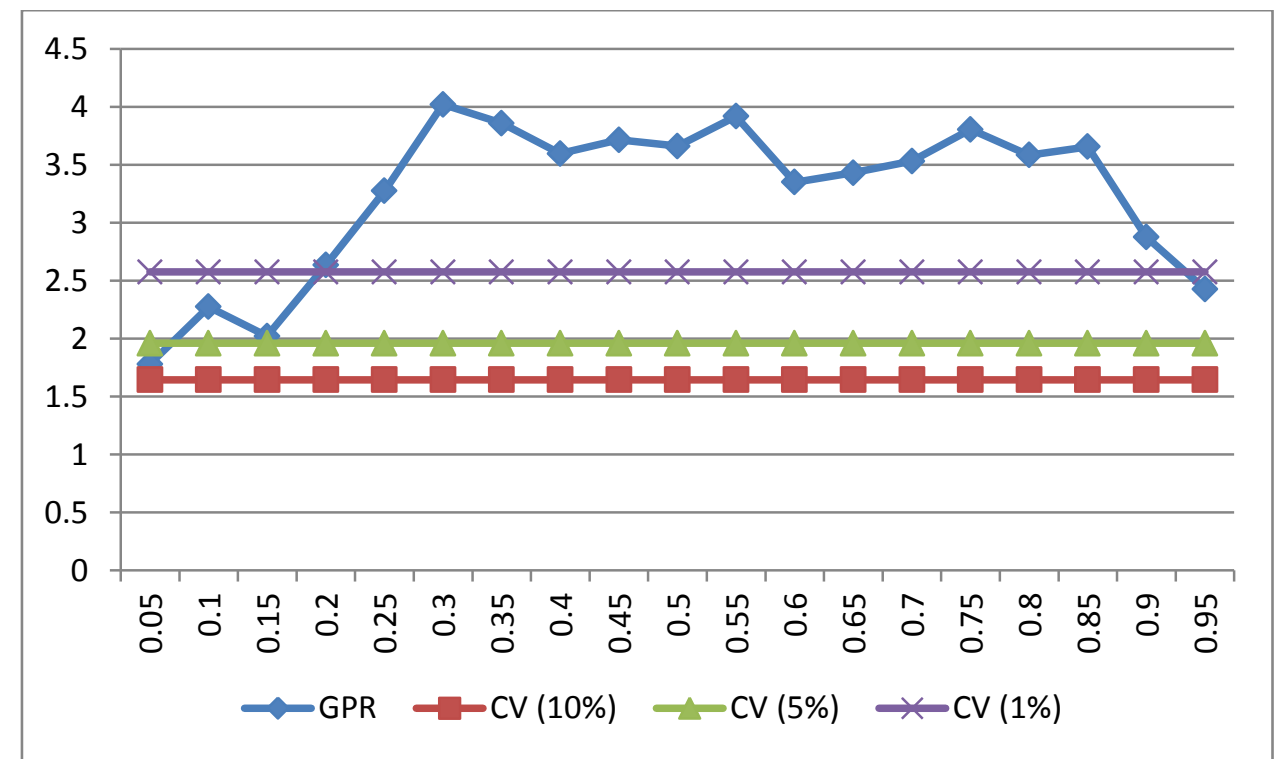

Notes: $\mathrm{CV}(10 \%), \mathrm{CV}(5 \%)$ and $\mathrm{CV}(1 \%)$ are the 10, 5, and 1 percent critical values of $1.645,1.96$, and 2.575 respectively. The horizontal axis measures the various quantiles while the vertical axis captures the tests statistic. The lines corresponding to GPR shows the rejection (non-rejection) of the null of no Granger causality from the various GPRs on DJIA volatility jumps at the 10, 5, and 1 percent levels, if the lines are above (below) 1.645, 1.96 and 2.575 respectively for a specific quantile.

\footnotetext{
${ }^{3}$ Note that, Caldara and Iacoviello (2017) further disentangle the direct effect of adverse global geopolitical events from the effect of pure geopolitical risks by constructing two indexes: The Geopolitical Threats index (GPRT), which only includes words belonging to Search groups 1 to 4 (discussed above in the Data segment), and the Geopolitical Acts index (GPRA) only includes words belonging to Search groups 5 and 6 (discussed in the Data section of the paper). We observed that GPRT was able to significantly predict volatility jumps at the 1 percent level over the quantile range of 0.15 to 0.90 , while the null was rejected at the 5 percent level for the extreme quantiles of 0.05 and 0.95 . As far as GPRA was concerned, the null was rejected at the 5 percent level over the quantile ranges of 0.25 to 0.50 and 0.75 to 0.90 , while predictability at the 10 percent level was observed for the remaining quantiles, barring the extreme ends of 0.05 and 0.95 , where no causality was detected. Interestingly, these results suggested that threats seem to matter more for jumps than actual acts. Complete details of these results have been presented in Figure A2 in the Appendix of the paper.

4 Based on the suggestion of an anonymous referee, following Uddin et al., (2018), we analysed the role of alternative measures of economic uncertainty in predicting volatility jumps. Given our objective to look at long-span jumps, we used the historical economic policy uncertainty (EPU) index of Baker et al., (2016) which covers the period of 1900:01 to 2014:10, and the news-based volatility index (NVIX) of Manela and Moreira (2017) covering the period of 1889:07 to 2016:03. While the results based on the NVIX mirrors that of the GPRs, the EPU is found to predict the volatility jumps over the quantile range of 0.25 to 0.85 . Complete details of these results are available upon request from the authors.
} 


\subsection{Robustness Analysis}

Based on the suggestions of an anonymous referee, we also repeated our analysis using the crossquantilogram approach of Han et al., (2016). The cross-quantilogram measures quantile dependence and tests for directional predictability between two time series $\left(x_{1}\right.$ and $\left.x_{2}\right)$. The sample cross-quantilogram of Han et al., (2016) is defined as:

$$
\hat{\rho}_{\alpha}(k)=\frac{\sum_{t=k+1}^{T} \psi_{a 1}\left(x_{1 t}-\hat{q}_{1}\left(a_{1}\right)\right) \psi_{a 2}\left(x_{2 t-k}-\hat{q}_{2}\left(a_{2}\right)\right)}{\sqrt{\sum_{t=k+1}^{T} \psi_{a 1}^{2}\left(x_{1 t}-\hat{q}_{1}\left(a_{1}\right)\right)} \sqrt{\sum_{t=k+1}^{T} \psi_{a 2}^{2}\left(x_{2 t-k}-\hat{q}_{2}\left(a_{2}\right)\right)}}
$$

for $k=0, \pm 1, \pm 2, \ldots$, given a set of quantiles, the cross-quantilogram considers dependency in terms of the direction of deviation from quantiles, and thus, measures the directional predictability from one series to another. By construction, $\hat{\rho}_{a}(k) \in[-1,1]$ with $\hat{\rho}_{a}(k)=0$ corresponding to the case of no directional predictability.

For our application we consider a very large number of lags in the framework of the quantilogram. We consider lags of $k=60$ which represents 5 years. In Figures 2-4, we provide the cross-quantilogram $\hat{\rho}_{a}(k)$ and the portmanteau tests $\hat{Q}_{a}^{p}$ (i.e., the Box-Ljung version) to detect directional predictability from GPRs to volatility jumps. For the quantiles of volatility jumps $q_{1}\left(a_{1}\right)$ we consider a wide range for $a_{1}=0.05,0.1,0.2,0.3,0.5,0.7,0.8,0.9$ and 0.95. For the quantiles of GPRs $q_{2}\left(a_{2}\right)$ we consider $a_{2}=0.1,0.5$ and 0.9 . In each graph, we show the $95 \%$ bootstrap confidence intervals of no predictability based on 1,000 bootstrapped replications.

From the figures 2(a) and 2(b), which are for the case when the GPRs is in the lower quantile, i.e., $a_{2}=0.1$, we observe that there is no significant relationship between volatility jumps at lower quantiles and GPRs. On the other hand, the cross-quantilograms $\hat{\rho}_{a}(k)$ for $a_{1}=0.8,0.9$ and 0.95 are negative and significant for some lags. This mean that when GPRs is very low, it is unlikely to cause large volatility jumps. From the figures $3(\mathrm{a})$ and $3(\mathrm{~b})$, which represent the case when the GPRs is in the median, i.e., $a_{2}=0.5$, we observe in some quantiles for some lags of the conditional distribution of volatility jumps, a significant positive directional predictability from GPRs to volatility jumps. Finally, from the figures 4(a) and 4(b), which are for the case when the GPRs is in higher quantile, i.e., $a_{2}=0.9$, we observe that the crossquantilograms $\hat{\rho}_{a}(k)$ for $a_{1}=0.05,0.1,0.2,0.3,0.5,0.7,0.8,0.9$ and 0.95 are positive and significant for some lags, especially when volatility jumps are in higher quantile. This means that 
when GPRs is very high, it is likely to cause very large volatility jumps. In sum, as observed from the results, in general, higher values of GPRs is likely to have a strong positive impact on volatility jumps over its entire conditional distribution, relative to when GPRs is low, in which case the effect on volatility jumps is quite weak.

Figure 2. Cross-Quantilograms for lower levels of GPRs
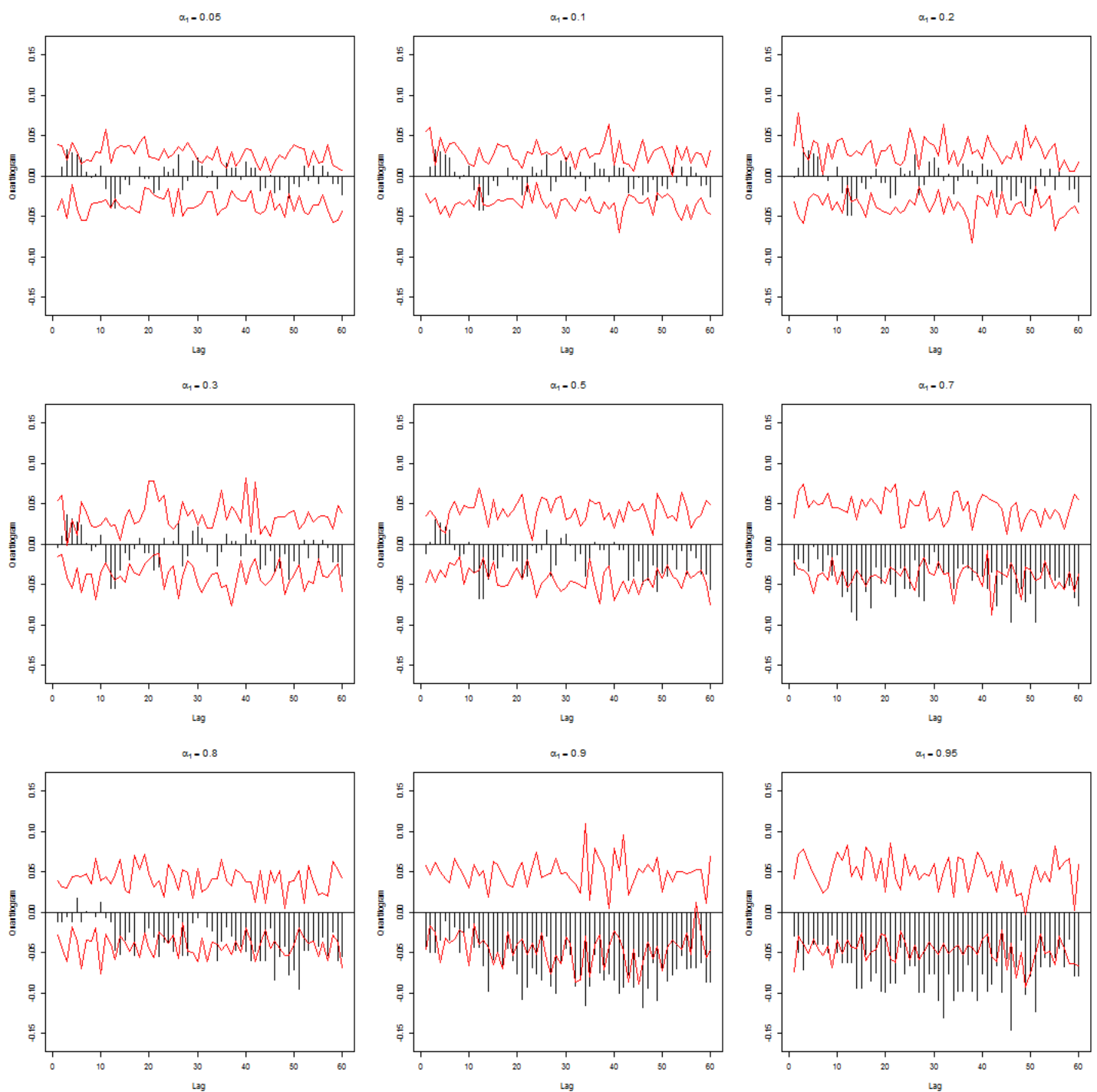

Figure 2(a). The sample cross quantilogram $\hat{\rho}_{a}(k)$ for $a_{2}=0.1$ to detect directional predictability from GPRs to DJIA Volatility Jumps. Bar graphs describe sample cross-quantilograms and lines are the $95 \%$ bootstrap confidence intervals. 


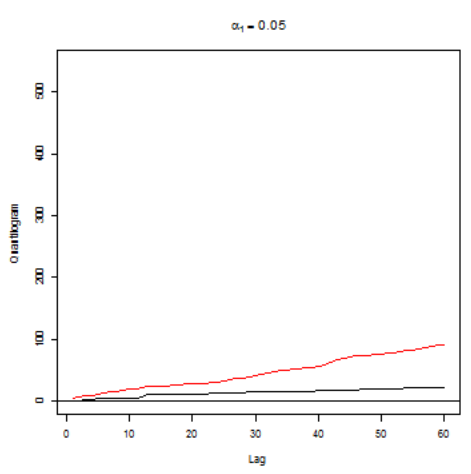

$\alpha_{1}-0.3$

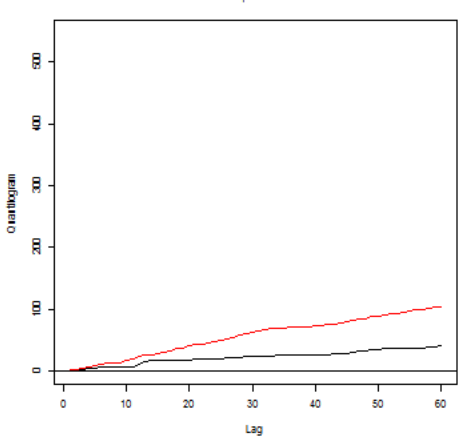

$\alpha_{1}=0.8$

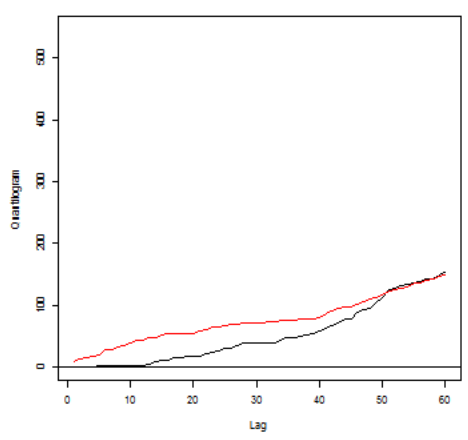

$a_{1}-0.1$

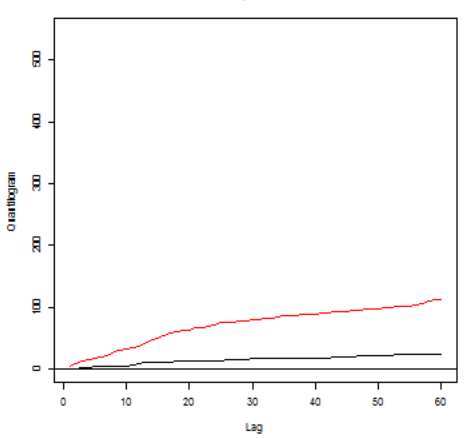

$\alpha_{1}=0.5$

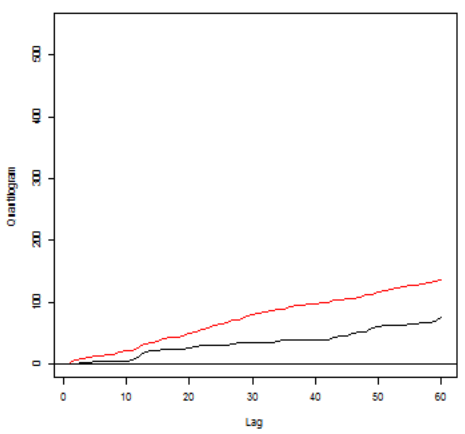

$\alpha_{1}=0.9$

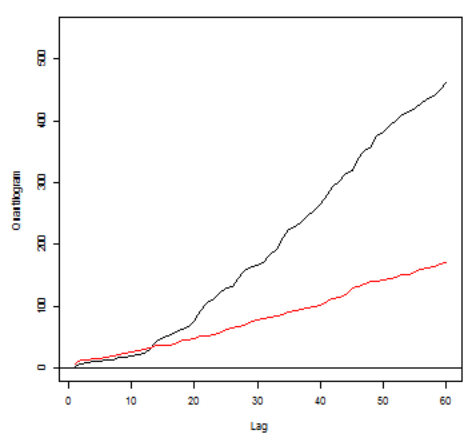

$a_{1}-0.2$

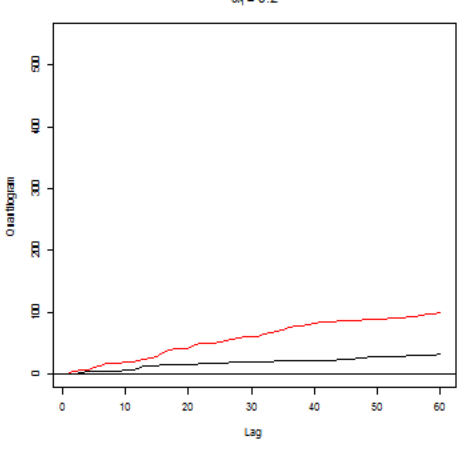

$a_{1}-0.7$

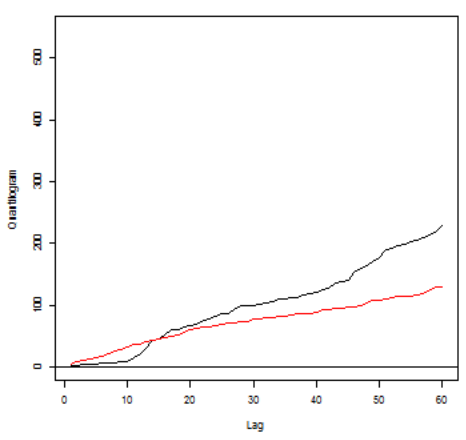

$\alpha_{1}-0.95$

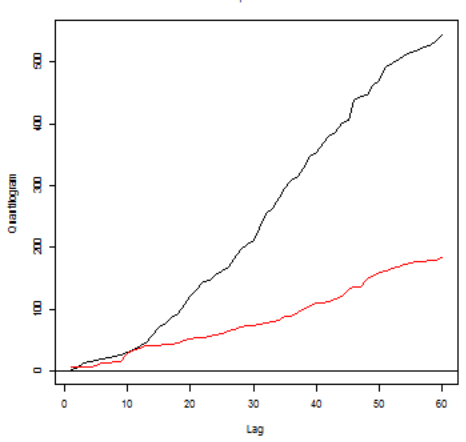

Figure 2(b). Box-Ljung test statistic $\hat{Q}_{a}^{(p)}$ for each $\operatorname{lag} p$ and quantile $a$ using $\hat{\rho}_{a}(k)$ with $a_{2}=0.1$. The dashed lines are the $95 \%$ bootstrap confidence intervals. 
Figure 3. Cross-Quantilograms for moderate levels of GPRs
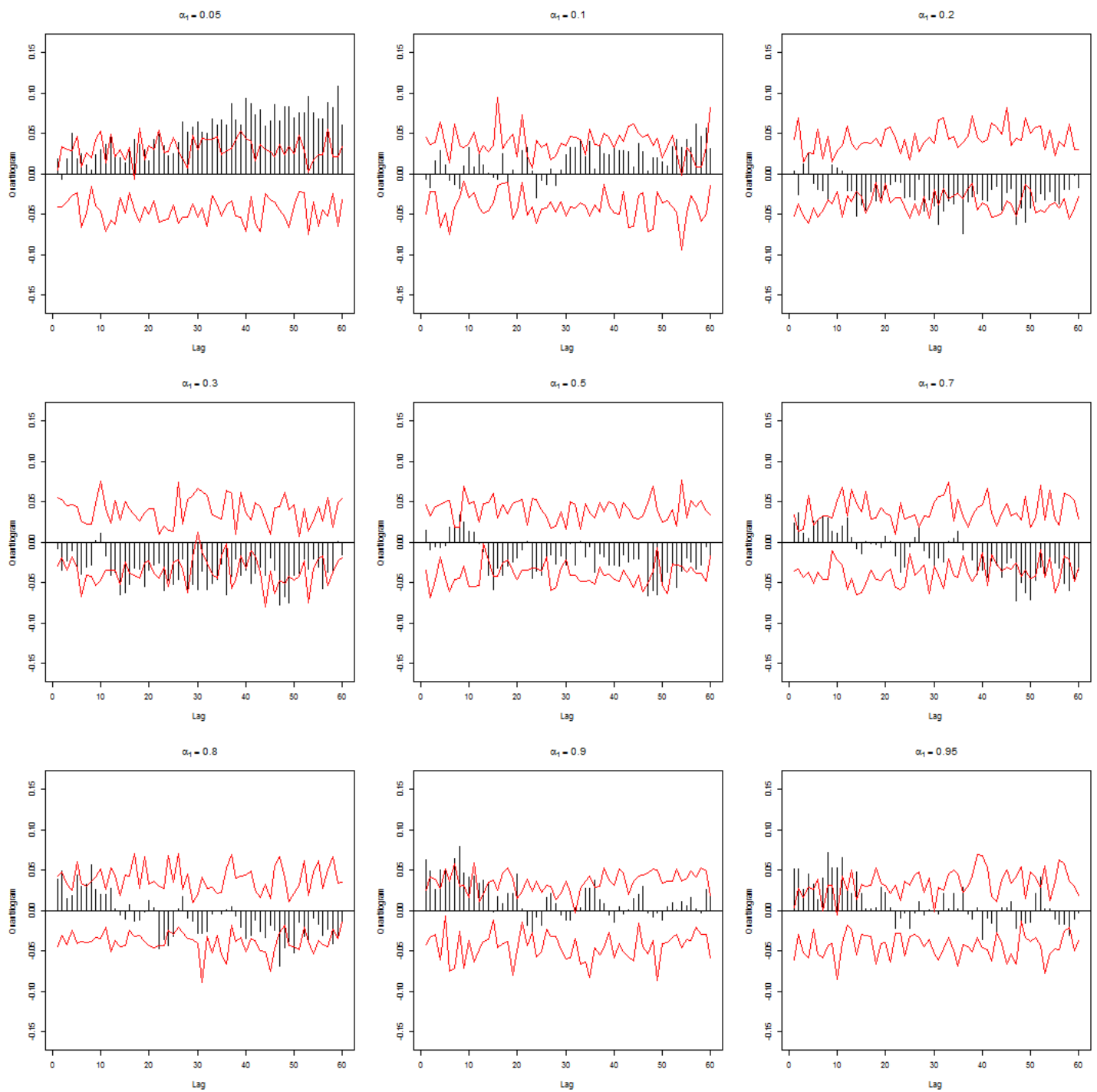

Figure 3(a). The sample cross quantilogram $\hat{\rho}_{a}(k)$ for $a_{2}=0.5$ to detect directional predictability from GPRs to DJIA Volatility Jumps. Bar graphs describe sample cross-quantilograms and lines are the $95 \%$ bootstrap confidence intervals. 


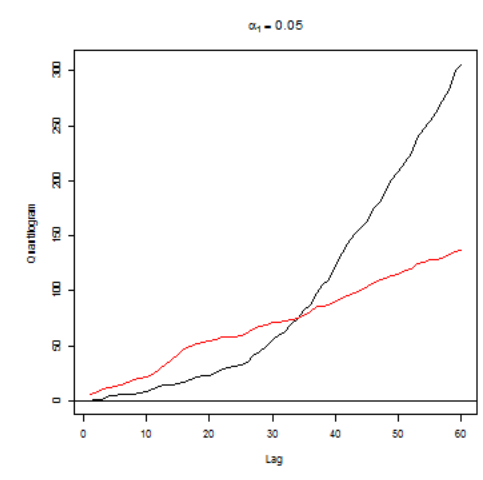

$\alpha_{1}-0.3$

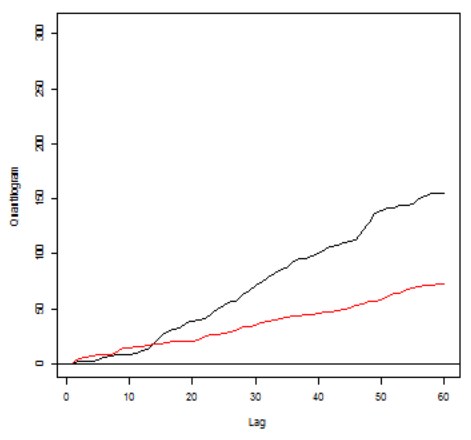

$\alpha_{1}-0.8$

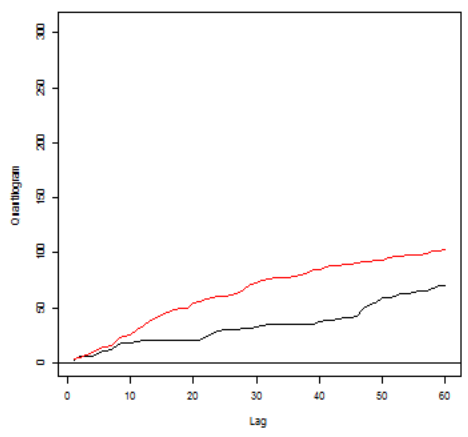

$\alpha_{1}=0.1$

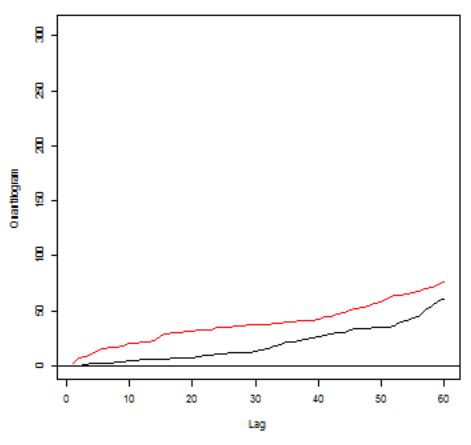

$a_{1}-0.5$

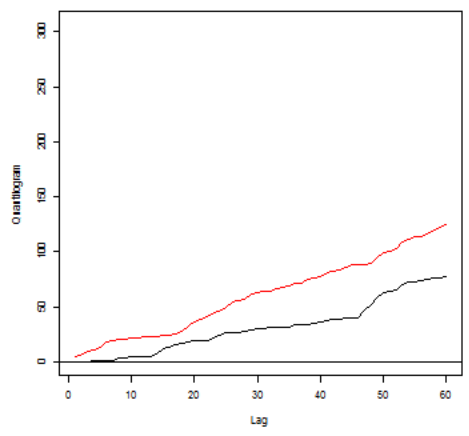

$a_{4}-0.9$

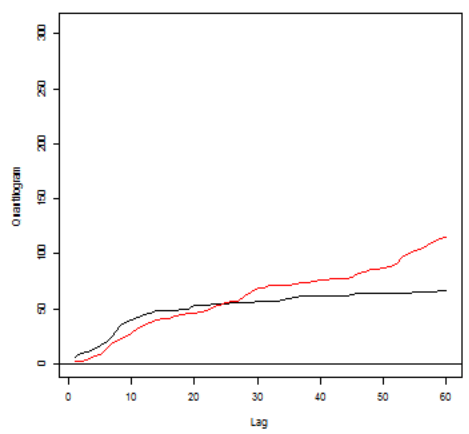

$a_{1}-0.2$

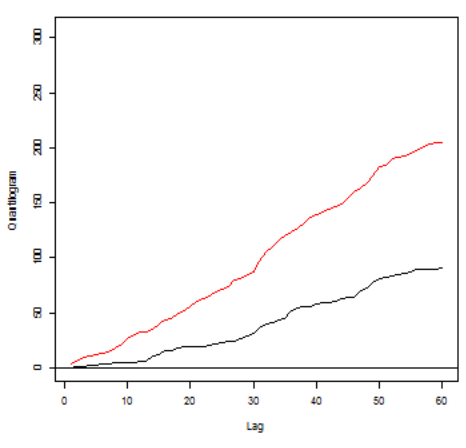

$a_{1}-0.7$

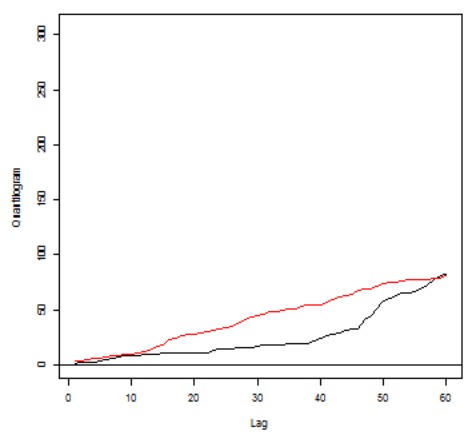

$a_{1}-0.95$

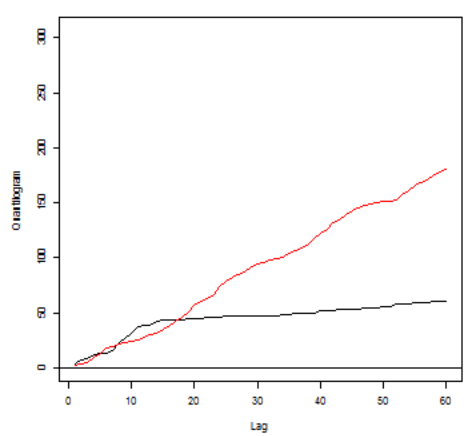

Figure 3(b). Box-Ljung test statistic $\hat{Q}_{a}^{(p)}$ for each lag $p$ and quantile $a$ using $\hat{\rho}_{a}(k)$ with $a_{2}=0.5$. The dashed lines are the $95 \%$ bootstrap confidence intervals. 
Figure 4. Cross-Quantilograms for higher levels of GPRs
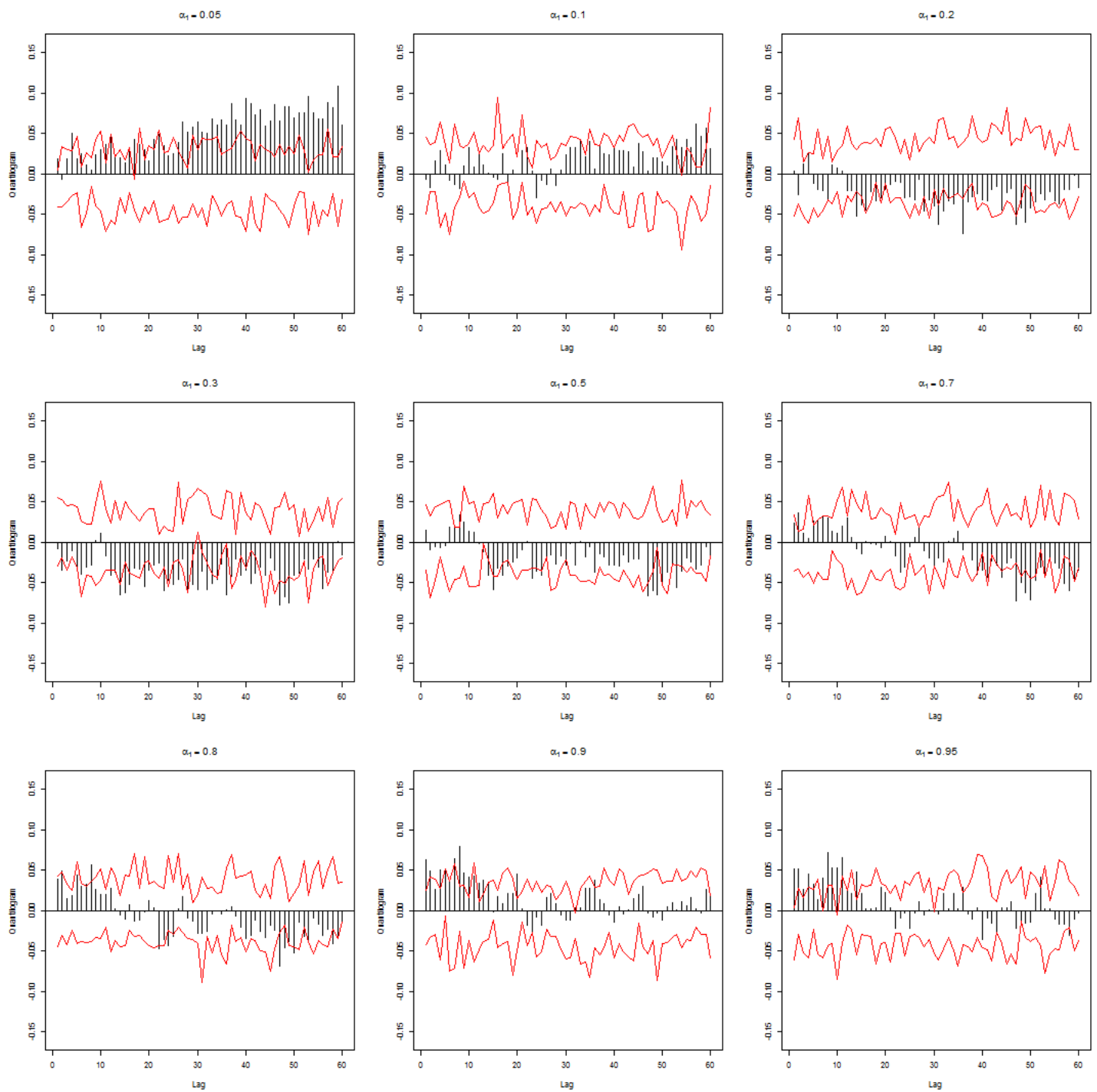

Figure 4(a). The sample cross quantilogram $\hat{\rho}_{a}(k)$ for $a_{2}=0.9$ to detect directional predictability from GPRs to DJIA Volatility Jumps. Bar graphs describe sample cross-quantilograms and lines are the $95 \%$ bootstrap confidence intervals. 


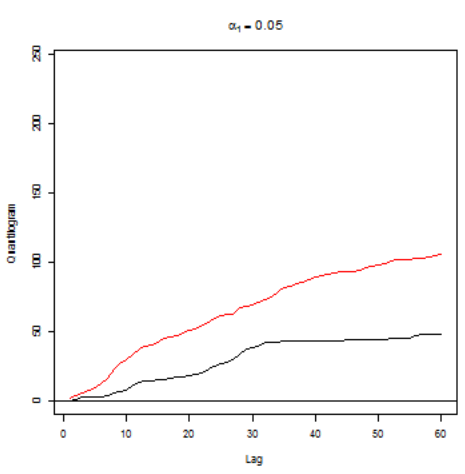

$\alpha_{1}-0.3$

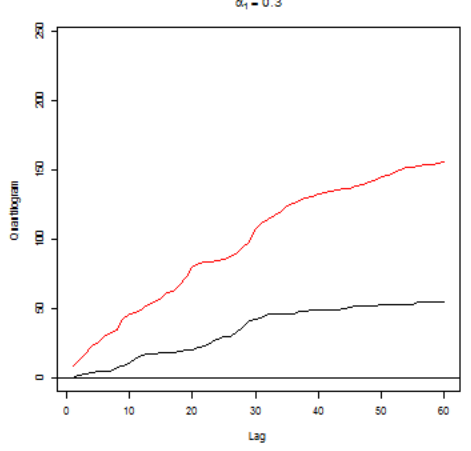

$\alpha_{1}=0.8$

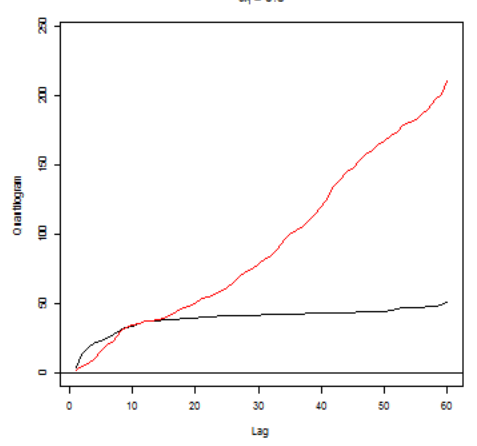

$a_{1}-0.1$

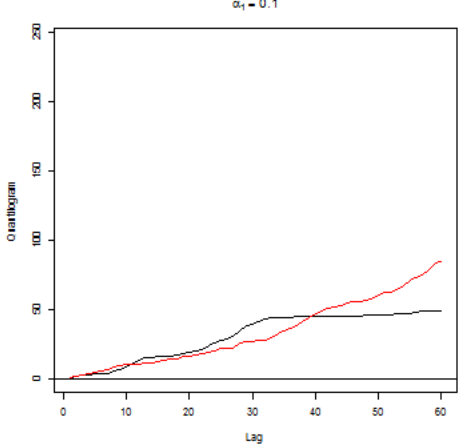

$a_{4}-0.5$

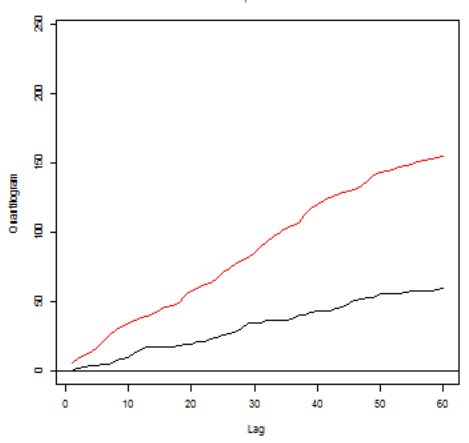

$a_{1}-0.9$

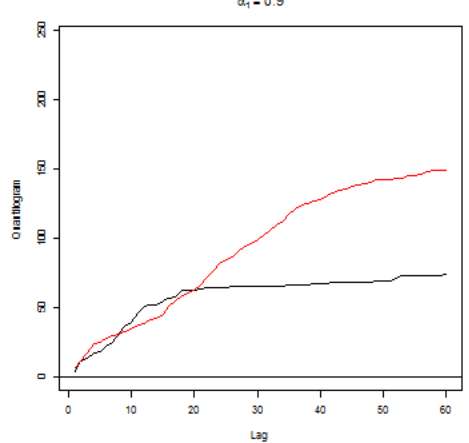

$a_{1}-0.2$

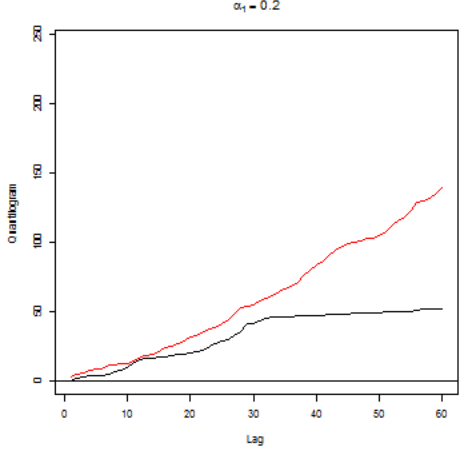

$a_{4}-0.7$

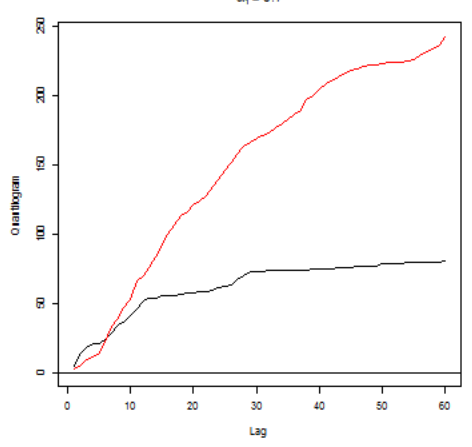

$\alpha_{1}-0.95$

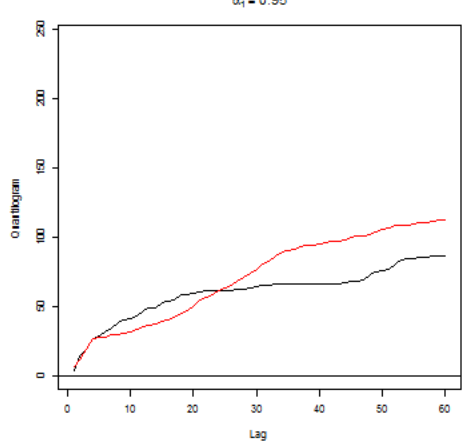

Figure 4(b). Box-Ljung test statistic $\hat{Q}_{a}^{(p)}$ for each lag $p$ and quantile $a$ using $\hat{\rho}_{a}(k)$ with $a_{2}=0.9$. The dashed lines are the $95 \%$ bootstrap confidence intervals.

\section{Conclusions}

In the recent volatility-related literature, it has been stressed that jumps in volatility can improve the overall fit of volatility models. Therefore, a large literature has developed trying to not only model volatility jumps, but also attempting to explain the causes behind such jumps based on financial variables, and more recently, news. Given this, in this paper we analysed the role of a news-based index of geopolitical risks (GPRs), in predicting volatility jumps in the Dow Jones Industrial Average (DJIA) over the monthly period of 1899:01 to 2017:12, with the jumps having been computed based on daily data over the same period. For our predictability analysis, we rely on a nonparametric causality-in-quantiles test, which in turn, is robust to misspecication due to nonlinearity and structural breaks being a data-driven procedure. 
Starting off with the standard linear causality test, we were unable to detect any evidence of GPRs causing volatility jumps. But, we indicated that linear Granger causality test results cannot be relied on because formal tests reveal strong evidence of nonlinearity and structural breaks between jumps and GPRs. Hence, linear Granger causality tests are misspecified. When we used the nonparametric causality-in-quantiles test instead, we were able to detect overwhelming evidence rejecting the null hypothesis that GPRs does not Granger causes jumps over the entire conditional distribution of the latter. Thus, our results indicated that when we control for misspecification due to nonlinearity and regime changes, it is indeed true that geopolitical events can predict movements in volatility jumps of the DJIA, irrespective of the size of such jumps. A cross-quantilogram analysis helps us to qualify these results further by showing that what matters most for increases in volatility jumps are relatively higher than lower GPRs. Given that daily data on GPRs are also available over a shorter sample period, as part of future research it would be interesting to extend this paper to a multi-country analysis, whereby volatility jumps could be obtained using intraday data on stock markets of various developed and developing economies.

\section{References}

Andersen T.G., Dobrev, D., and Schaumburg, E. (2012). Jump-robust volatility estimation using nearest neighbor truncation. Journal of Econometrics, 169(1), 75-93.

Apergis, N., Bonato, M., Gupta, R., and Kyei, C. 2017. Does Geopolitical Risks Predict Stock Returns and Volatility of Leading Defense Companies? Evidence from a Nonparametric Approach. Defence and Peace Economics, DOI: http://dx.doi.org/10.1080/10242694.2017.1292097.

Bai, J. and Perron, P., 2003. Computation and analysis of multiple structural change models. Journal of Applied Econometrics, 18(1), pp. 1-22

Baker, S., Bloom, N., and Davis, S. (2016). Measuring economic policy uncertainty. Quarterly Journal of Economics, 131, 1593-1636

Baker, S.R., Bloom, N., Davis, S.J., and Sammon, M. (2018). What triggers stock market jumps? American Economic Association (ASSA) Meetings, Philadelphia, PA, January 7th, 2018.

Balcilar, M., Bonato, M., Demirer, R., and Gupta R. (2017). The effect of investor sentiment on gold market return dynamics: Evidence from a nonparametric causality-in-quantiles approach. Resources Policy, 51(C), 77-84.

Balcilar, M., Bonato, M., Demirer, R., and Gupta, R. Forthcoming. Geopolitical Risks and Stock Market Dynamics of the BRICS. Economic Systems. 
Bekaert, G., and Hoerova, M. (2014). The VIX, the variance premium and stock market volatility. Journal of Econometrics, 183(2), 181-192.

Bollerslev, T., Todorov, V., and Li, S-Z. (2013). Jump tails, extreme dependencies, and the distribution of stock returns. Journal of Econometrics, 172(2), 307-324.

Boudoukh,J., Feldman, R., Kogan, S., and Richardson, M. (2015). News and Stock Prices: New Insights. Arison School of Business, IDC Herzliya, Mimeo.

Bouras, C., Christou, C., Gupta, R., and Suleman, T. (Forthcoming). Geopolitical Risks, Returns and Volatility in Emerging Stock Markets: Evidence from a Panel GARCH Model. Emerging Markets Finance and Trade.

Bouri, E., Demirer, R., Gupta, R., and Marfatia, H.A. (Forthcoming). Geopolitical Risks and Movements in Islamic Bond and Equity Markets: A Note. Defence and Peace Economics.

Brock, W., Dechert, D., Scheinkman, J., LeBaron, B., 1996. A test for independence based on the correlation dimension. Econometric Reviews, 15, 197-235.

Broadie, M., Chernov, M., and Johannes, M. (2007). Model specification and risk premia: Evidence from futures options. The Journal of Finance, 62, 1453-1490.

Caldara, D., and Iacoviello, M. 2017. Measuring Geopolitical Risk. Working Paper, Board of Governors of the Federal Reserve Board.

Caporin, M., Rossi, E., and Santucci de Magistris, P. (2016). Volatility jumps and their economic determinants. Journal of Financial Econometrics, 14(1), 29-80.

Corsi F., Pirino, D., and Renò, R. (2010). Threshold bipower variation and the impact of jumps on volatility forecasting. Journal of Econometrics, 159(2), 276-288.

Cutler, D.M., Poterba, J.M., and Summers, L.H. (1989). What Moves Stock Prices? Journal of Portfolio Management, 15(3), 4-12.

Diks, C. G. H., and Panchenko, V. 2005. A note on the Hiemstra-Jones test for Granger noncausality. Studies in Nonlinear Dynamics and Econometrics, 9(2), 1-7.

Diks, C. G. H., and Panchenko, V. 2006. A new statistic and practical guidelines for nonparametric Granger causality testing. Journal of Economic Dynamics and Control, 30(9-10), 1647-1669.

Duffie, D., Pan, J., and Singleton, K. (2000). Transform analysis and asset pricing for affine jump diffusions. Econometrica, 68, 1343-1376.

Duong, D., and Swanson, N. R. (2015). Empirical evidence on the importance of aggregation, asymmetry, and jumps for volatility prediction. Journal of Econometrics, 187(2), 606-621.

Eraker, B., Johannes, M. S., and Polson, N. G. (2003). The impact of jumps in returns and volatility. Journal of Finance, 53(3), 1269-1300. 
Giot, P., Laurent, S., and Petitjean, M. (2010). Trading activity, realized volatility and jumps. Journal of Empirical Finance, 17(1):168-175.

Han, H., Linton, O., Oka, T., Whang, Y.J., 2016. The cross-quantilogram: Measuring quantile dependence and testing directional predictability between time series. Journal of Econometrics, 193, 251-270.

Hiemstra, C. and Jones, J. D. 1994. Testing for linear and nonlinear Granger causality in the stock price-volume relation. Journal of Finance, 49, number 5, 1639-1664.

Hurvich, C.M. and Tsai, C.-L. 1989. Regression and Time Series Model Selection in Small Samples. Biometrika, 76, 297-307.

Jeong, K., Härdle, W. K. and Song, S., 2012. A consistent nonparametric test for causality in quantile. Econometric Theory, 28, 861-887.

Li, Q. and Racine, J.S. 2004. Cross-validated local linear nonparametric regression. Statistica Sinica, 14, 485-512.

Manela, A. and Moreira, A. 2017. News implied volatility and disaster concerns. Journal of Financial Economics, 123(1), 137-162.

Poon, S-H, and Granger, C. W. J. (2003). Forecasting Volatility in Financial Markets: A Review. Journal of Economic Literature, 41(2), 478-539.

Racine, J.S. and Li, Q. 2004. Nonparametric estimation of regression functions with both categorical and continuous data. Journal of Econometrics, 119, 99-130.

Todorov, V. and Tauchen, G. (2011). Volatility jumps. Journal of Business and Economic Statistics, 29(3):356-371. 


\section{APPENDIX A:}

Table A1. Summary Statistics

\begin{tabular}{|l|r|r|}
\cline { 2 - 3 } \multicolumn{1}{c|}{} & \multicolumn{2}{c|}{ Variable } \\
\hline Statistic & JUMP & \multicolumn{1}{c|}{ GPRs } \\
\hline Mean & 0.0037 & 1.1322 \\
\hline Median & 0.0035 & 0.8050 \\
\hline Maximum & 0.0111 & 9.0600 \\
\hline Minimum & 0.0000 & 0.0700 \\
\hline Std. Dev. & 0.0016 & 1.0001 \\
\hline Skewness & 0.6358 & 2.5337 \\
\hline Kurtosis & 4.3190 & 12.0903 \\
\hline Jarque-Bera & 199.7393 & 6444.5220 \\
\hline$p$-value & 0.0000 & 0.0000 \\
\hline Observations & \multicolumn{2}{|c|}{1428} \\
\hline
\end{tabular}

Note: Std. Dev: stands for standard deviation; $p$-value corresponds to the Jarque-Bera test with the null of normality.

Table A2. Brock et al., (1996, BDS) Test of Nonlinearity

\begin{tabular}{|c|c|c|c|c|c|c|}
\hline \multirow{2}{*}{$\begin{array}{c}\text { Dependent } \\
\text { Variable }\end{array}$} & \multirow{2}{*}{$\begin{array}{c}\text { Independent } \\
\text { variable }\end{array}$} & \multicolumn{5}{|c|}{ Dimension } \\
\cline { 3 - 7 } & 2 & 3 & 4 & 5 & 6 \\
\hline $\begin{array}{c}\text { DJIA } \\
\text { Volatility } \\
\text { Jumps }\end{array}$ & GPRs & $8.9545^{*}$ & $10.6314^{*}$ & $11.5813^{*}$ & $12.3718^{*}$ & $13.1163^{*}$ \\
\hline
\end{tabular}

Note: Entries correspond to the z-statistic of the BDS test with the null of i.i.d. residuals, with the test applied to the residuals recovered from the jump equation with four lags each of the jump and GPRs variables; * indicates rejection of the null hypothesis at 1 percent level of significance. 
Figure A1. Data Plots

A1(a). DJIA Volatility Jumps

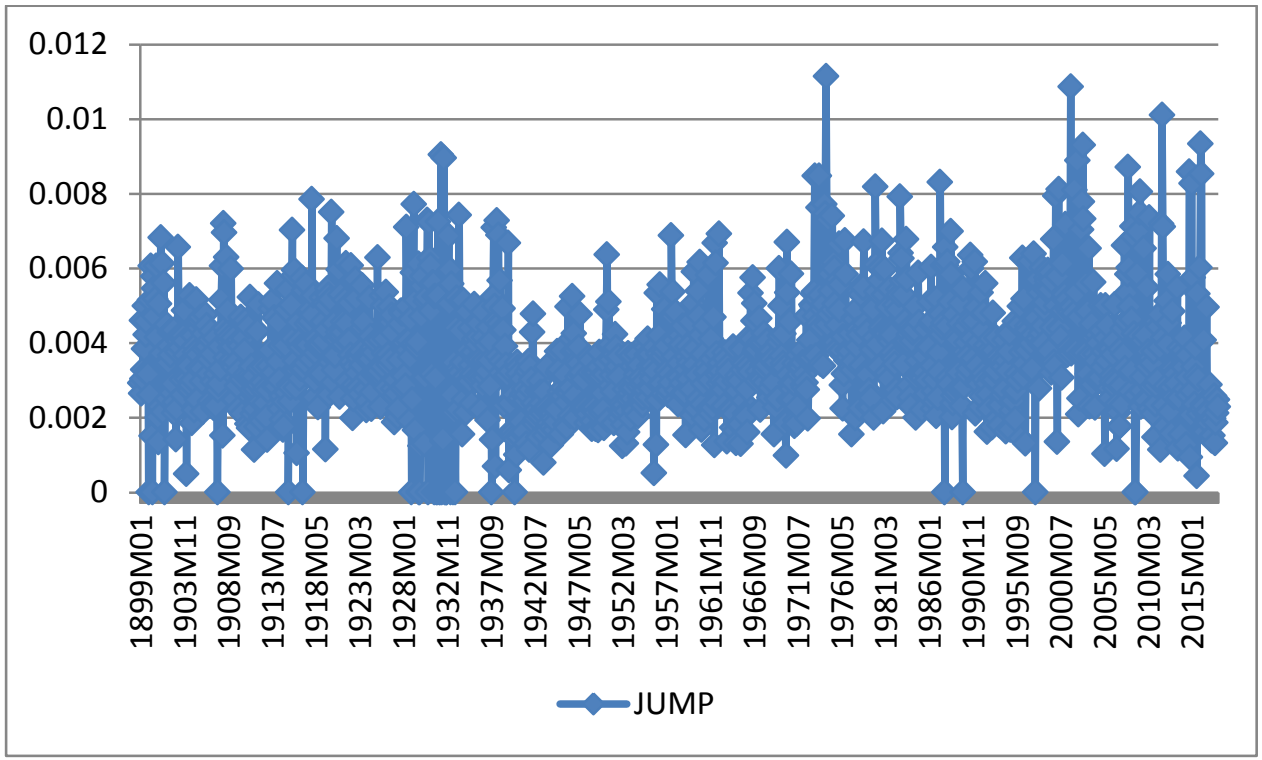

A1(b). Geopolitical Risks (GPRs)

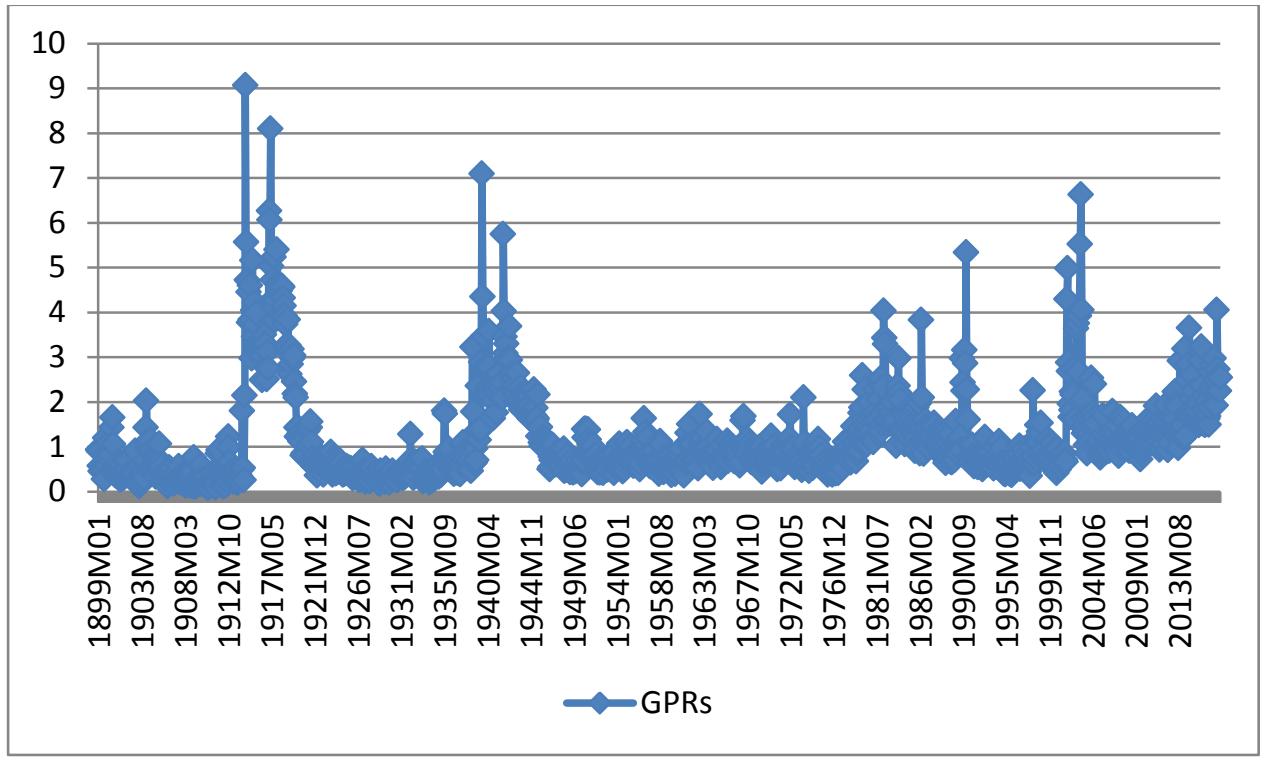


Figure A2. Causality-in-Quantiles Test Results for DJIA Volatility Jumps due to Threats of GPRs (GPRT) and Acts of GPRs (GPRA)

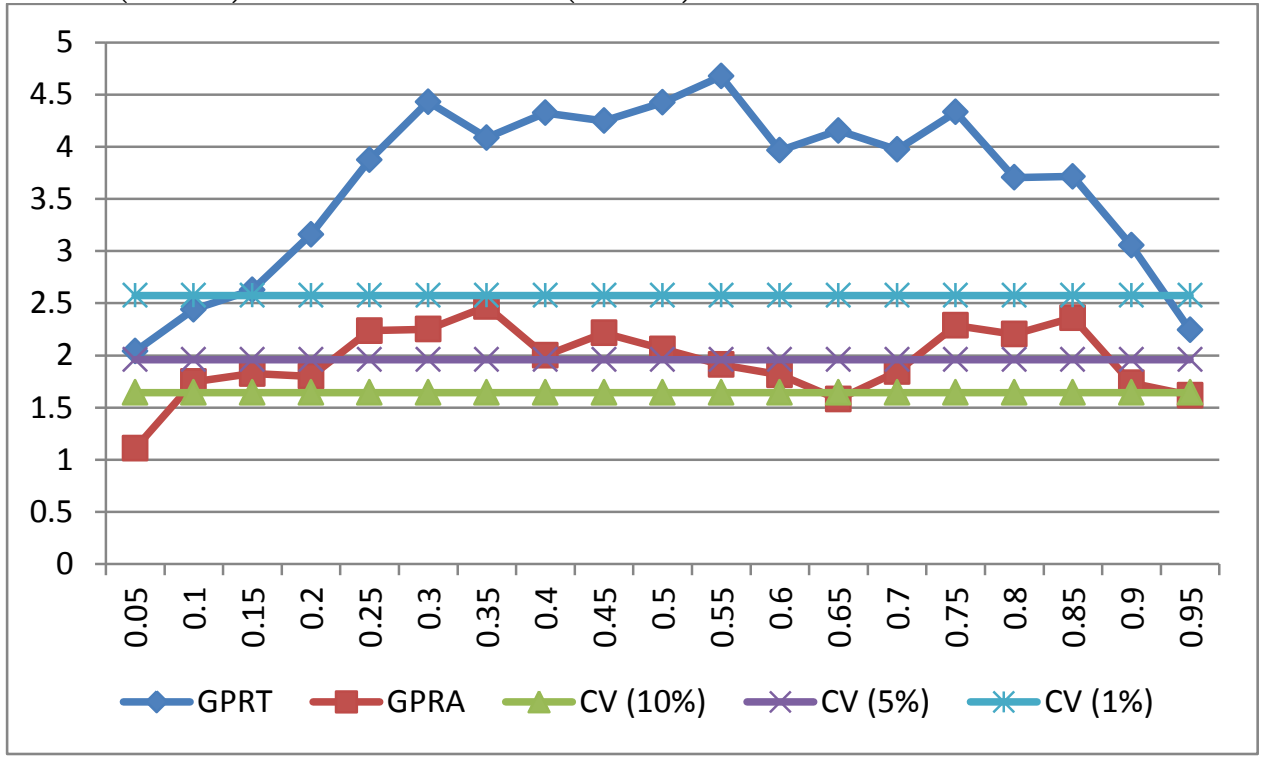

Notes: $\mathrm{CV}(10 \%), \mathrm{CV}(5 \%)$ and $\mathrm{CV}(1 \%)$ are the 10,5 , and 1 percent critical values of $1.645,1.96$, and 2.575 respectively. The horizontal axis measures the various quantiles while the vertical axis captures the tests statistic. The lines corresponding to GPRT and GPRA shows the rejection (non-rejection) of the null of no Granger causality from the various GPRT and GPRA respectively on DJIA volatility jumps at the 10, 5, and 1 percent levels, if the lines are above (below) 1.645, 1.96 and 2.575 respectively for a specific quantile. 